\title{
LOS CRÍTICOS, LOS ARTISTAS Y LA PINTURA ABSTRACTA EN LA ESPAÑA DE POSTGUERRA
}

\author{
POR \\ JULIÁN DÍAZ SÁNCHEZ \\ Universidad de Castilla-La Mancha
}

\begin{abstract}
El presente trabajo revisa algunas de las actitudes que artistas y críticos de arte adoptaron frente a la pintura informal en la España de la postguerra.

Palabras clave: Pintura. S. xx. Crítica de Arte. Pintura abstracta.

This article deals with some attitudes of the artists and criticals of Art in the face of the Abstract Painting in the spanish postwar.

Key words: Painting. xxth century. Art criticism. Abstract Painting.
\end{abstract}

La I Bienal Hispanoamericana de Arte ${ }^{1}$, celebrada en Madrid en 1951, sirvió, entre otras cosas, para plantear, en toda su crudeza, la necesidad de una modernización artística en el país y poner algunas bases para la misma. Desde entonces, una parte sustancial de la crítica de arte se manifestó a favor de la pintura abstracta y apoyó decididamente los éxitos de la misma en acontecimientos internacionales como la Bienal de São Paulo de 1957 o la de Venecia de $1958{ }^{2}$. La defensa teórica de la pintura abstracta, argumentada desde parámetros de españolidad y, por eso mismo, de coherencia con el régimen impuesto en 1939, se planteó en 1949 con las propuestas de la Escuela de Altamira ${ }^{3}$, que compartía algunos planteamientos estéticos con el grupo Pórtico. La historia escrita de la renovación artística bajo el franquismo parte de estos dos hechos; más conflictiva será la ubicación de Dau al Set, que se considerará más bien un epígono que el comienzo de la renovación artística de postguerra ${ }^{4}$. Será en el Primer Congreso de Arte

\footnotetext{
1 Un estudio minucioso y completo en Miguel Cabañas Bravo, Política artística del franquismo; Madrid, Consejo Superior de Investigaciones Científicas, 1996

${ }^{2}$ La participación española en las Bienales de Venecia se estudió en Rosalía Torrent, España en la Bienal de Venecia 1895-1997, Servicio de Publicaciones de la Diputación de Castellón, 1997. Para el papel de las Bienales de Venecia en la oficialización de la pintura abstracta véase Julián Díaz Sánchez, La "oficialización» de la vanguardia en la postguerra española (El Informalismo en la crítica de arte y los grandes relatos), Cuenca, Servicio de Publicaciones de la Universidad de Castilla-La Mancha, 1998.

${ }^{3}$ Expuestas en Ricardo Gullón, De Goya al arte abstracto (1953), Universidad de Puerto Rico, Riopiedras, 1963.

${ }^{4}$ Un ejemplo, entre otros muchos posibles, es el de José María Moreno Galván, «20 años en las letras y el arte de España. 1939-1959. La pintura», La Estafeta Literaria, Madrid, 1-5-59, pp. 8-11. Entre las posiciones contrarias, véase la de Arnau Puig, Els pros $i$ els contres de la pintura abstracta, Barcelona, Rafael Dalmau, 1963. El autor afirma que Dau al Set
} 
Abstracto de Santander de 1953 donde se obtenga, al menos en el plano teórico, una rotunda declaración a favor del arte abstracto; allí, según cuenta Vicente Aguilera Cerni, puede que con exageración, se puso en fuga a los «antiabstractistas» y los partidarios del arte abstracto «se encontraron con que habían estado batallando ... con unos auténticos fantasmas» ${ }^{5}$.

El apoyo al arte informal por una crítica esencialmente conservadora hubo de salvar algunos problemas: la consideración del Informalismo como una vanguardia vinculable al franquismo obligaba a situarlo históricamente en los parámetros de las tradiciones pictóricas españolas, algo a lo que los artistas contribuyeron de modo significativo a través de sus escritos. Tácitamente, la crítica desvinculaba al Informalismo de tendencias de vanguardia anteriores, el Surrealismo sobre todo, y también de la producción pictórica norteamericana para convertirlo en un producto genuinamente español ${ }^{6}$, un movimiento de sentido autárquico, una manifestación más de «lo español», un criterio, como es bien sabido, en alza durante el franquismo ${ }^{7}$. El grupo El Paso aparecía, por poner un ejemplo de los más conocidos, como portador de un arte con los pies en la tierra, «Y no sobre una tierra cualquiera — pecado de los cubistas y los surrealistas- sino sobre la tierra madre que nos nutre y nos da arrestos para el combate» ${ }^{8}$.

El favor de la crítica hacia la pintura abstracta precisó tanto de una relectura de la modernidad española, como de una conceptualización propia del arte abstracto que, sin ser radicalmente distinta a la que se hizo en otros países, no entró en contradicción con los principios ideológicos de catolicismo y españolidad que impuso el «Nuevo Estado» a partir de 1939. En las páginas que siguen tratamos de aportar algunos ejemplos en este sentido.

\section{LA RECONFIGURACIÓN DE LA VANGUARDIA HISTÓRICA}

La crítica de postguerra se ocupó en muchas ocasiones del Cubismo y el Surrealismo como tendencias situadas de alguna forma en el origen de la abstracción ${ }^{9}$, como veremos a continuación, el tratamiento de cada uno de los movimientos sería bien diferente.

Se atribuyó siempre al Cubismo un papel relevante en la génesis de la pintura abstracta, pero se consideró, al mismo tiempo, que este movimiento se situaba peligrosamente en la pendiente de la «deshumanización» ${ }^{10}$, en el sentido más orteguiano del término. La consideración del cubismo es ambivalente en la España de postguerra: el carácter austero que se le suele atribuir es coherente con los principios de orden, estructura y jerarquía que exigía a los pintores Eugenio d'Ors, un hombre extraordinariamente influyente en la época, y cuya influencia en la crítica y la historiografía está aún por calibrar; la españolidad de Picasso y Gris será un hecho

es el último intento de reconstrucción de la vanguardia cultural catalana de anteguerra, traicionado por el paso de algunos de sus componentes, especialmente Tàpies, a los modos pictóricos del Informalismo.

5 Vicente Aguilera Cerni, Panorama del nuevo arte español, Madrid, Guadarrama, 1966, p. 54.

${ }^{6}$ El proceso de «oficialización» de la pintura americana de postguerra en el contexto de la guerra fría, que favorecerá a la larga a la pintura española, fue analizado por Serge Guilbaut, De cómo Nueva York robó la idea de arte moderno, Madrid, Mondadori, 1990 (1983). Hay una severa refutación en David Craven, «Artistas internacionales, público nacional, mecenas locales», Dore Asthon, À rebours. La rebelión informalista [1939-1968] (catálogo exposición), Las Palmas de Gran Canaria, Madrid, CAAM, MNCARS, 1999, pp. 47-53.

${ }^{7}$ Un completo análisis en Javier Varela, La novela de España. Los intelectuales y el problema español, Madrid, Taurus, 1999

${ }^{8}$ Anónimo, «Señoras y señores», Papeles de Son Armadans, «Monográfico EL PASO», núm. 37, Palma de Mallorca, abril de 1959, p. 7. El autor es, con toda probabilidad, Camilo José Cela, director de la revista.

${ }^{9}$ Ricardo Gullón (ed.), El arte abstracto y sus problemas, Madrid, Publicaciones de Cultura Hispánica, 1956, recoge las ponencias del «Primer Congreso de Arte Abstracto» celebrado la Universidad Internacional Menéndez Pelayo de Santander en 1953.

${ }^{10}$ La primera idea se expresa con unanimidad total en AA.VV., El arte abstracto y sus problemas, op. cit., la segunda es de Luis Felipe Vivanco, «El arte humano», Escorial. Revista de Cultura y Letras, Cuaderno 1, Madrid, noviembre de 1940, pp. 141-150

$A E A, \mathrm{LXXV}, 2002,297$, pp. 39 a 50 
aprovechable y siempre subrayado. En general, se considera el cubismo como un movimiento pionero, aunque superado, que abrió importantes caminos, en especial el de la pintura abstracta. Es el sentido que tiene la alabanza dirigida por Tharrats a Juan Gris, «que podríamos clasificar con certeza entre los diez pintores más importantes de nuestro tiempo» ${ }^{11}$. Hay, en el artículo, una referencia velada a Picasso, seguramente destinatario de una alusión a ciertos artistas desatendidos en el interior del país, a los que, «porque no hemos estado de acuerdo con sus ideas, con algunas de sus excentricidades, con su humor, hemos puesto en olvido su relevante personalidad» ${ }^{12}$. Para Tharrats, la operación estética fundamental de Juan Gris había sido la reconversión de la realidad «a veces demasiado brutal y descriptiva, para devolverla más poética». El valor fundamental de Gris era su distancia de los realismos (leída aquí como baluarte contra el academicismo) y su coherencia con la tradición, articulada mediante la tópica comparación de Gris con Zurbarán.

Muy interesante resulta la consideración del Surrealismo en los años cincuenta: se le atribuye un papel relevante en el origen de la pintura abstracta, con la que podría tener en común el uso de los métodos automáticos, aunque los resultados de uno y otra serán muy diferentes para la crítica ${ }^{13}$; sin embargo, una de las bondades más alabadas del arte abstracto radica en su distanciamiento del movimiento de Bretón, ante el que se mantendrán importantes reservas. Especialmente significativas, por su cercanía al movimiento, son las de Juan Eduardo Cirlot:

«Agradezco al surrealismo todo cuanto nos ha dado, pero me siento a cierta distancia de sus posiciones en muchos aspectos. Quiero tener cada día más lejos de mí el culto al erotismo, aún en sus aspectos sublimes. Mi colección de espadas solamente surgió de la necesidad de establecer un sistema de idealismo viril contra la adoración prosternada de la mujer, tanto en su aspecto de imagen puramente cristalizada como la Beatriz de Dante, como en los aspectos vulgarizados por las revistas pornográficas» ${ }^{14}$.

En general, la descalificación del Surrealismo por la crítica se debe a dos razones primordiales: su vinculación a la España de los años 30, que implica un alto nivel de politización, y su consideración como un movimiento anticristiano. Frente al Surrealismo, se optaba por un arte de carácter más austero y de más abiertas posibilidades de lectura. En 1952 Luis Felipe Vivanco comparaba la pintura de Aguayo con la de Saura y consideraba que la del primero, muy influida por el Surrealimo en aquella época, resultaba muy anticuada «y es porque lo de Dalí o lo de Tanguy, por más minuciosamente elaborado, se ha quedado más anticuado y con menos vigencia plástica o poética que lo de Klee o lo de Picasso» ${ }^{15}$. Hay que entender las consideraciones de Vivanco como favorables a una pintura más constructiva (más «orsiana») frente a un Surrealismo condenado sin paliativos por Eugenio d'Ors en sus Salones de los Once. Un hombre como Eduardo Westerdhal, muy vinculado en otro tiempo al Surrealismo, decía, en referencia a Will Faber que «ha sustituido los objetos morbosos y delicuescentes del

\footnotetext{
11 J. J. Tharrats, «Hace veinticinco años que murió Juan Gris», Revista, núm. 16, Barcelona, 31-7-52, p. 10.

12 Esta posición respondía al ideario oficial de la publicación, desde la que Dionisio Ridruejo, en su artículo «Excluyentes y comprensivos» (Revista, núm. 26, Barcelona, 9-10-52, p. 2) postulaba la recuperación de escritores como Unamuno o Miguel Hernandez; el artículo motivó una furibunda respuesta por parte del general Juan Vigón, quien, a través de La Vanguardia, se oponía a que se presentase a esos escritores como maestros o arquetipos de españoles, véase J. J. Sánchez Aranda y C. Barrera del Barrio, Historia del periodismo español, desde sus orígenes hasta 1975, Pamplona, EUNSA, 1992, p. 457. Véase también Javier Varela, op. cit.

${ }^{13}$ Es la tesis de Juan Eduardo Cirlot, «Explicación de las pinturas de Antonio Tapies», Destino, núm. 949, Barcelona 15-10-55, p. 34.

${ }^{14}$ Citado en Edouard Jaguer, «Sobre un diálogo inconcluso», AA.VV. Mundo de Juan Eduardo Cirlot (Catálogo exposición), Valencia, Generalitat Valenciana, Conselleria de Cultura, Educació i Ciència, 1996, p. 33.

${ }^{15}$ Luis Felipe Vivanco, «Los viejos y los jóvenes», Revista, núm 14, Barcelona, 17-7-52, p. 11.
} 
surrealismo por otros de valores abstractos, de la línea evocadora de la limpidez de la línea cotidiana» ${ }^{16}$. En la crítica de los años cincuenta, y aún antes, el Surrealismo se configura como contramodelo y la literatura artística española de esta época es más pródiga de lo que podría parecer en condenas tajantes a este movimiento plástico.

Los triunfos internacionales del Informalismo abocarían a la crítica a buscar antecedentes a esta situación. En 1960 se celebró en la Sala Darro de Madrid la exposición Arte español 1925-1935; su comisario, José María Moreno Galván, pretendía llevar a cabo una revisión de la vanguardia de anteguerra, pero Luis Figuerola Ferretti, al tiempo que saludaba la iniciativa, la vinculaba con los tiunfos del arte español en los años cincuenta: «Si el arte contemporáneo conoce entre nosotros bazas importantes ganadas a la actualidad internacional, era ya imprescindible pensar en situar o establecer ciertos jalones entre los cuales se hace más fácil y comprensible aquél» ${ }^{17}$.

La Exposición de Artistas Ibéricos, que aparecía reseñada en la muestra, habría sido, para el crítico citado, uno de esos «jalones». Figuerola-Ferretti concluía que la historia del arte español se desarrollaba, por causas de idiosincrasia nacional, a saltos. Los momentos de internacionalización del arte español se alternaban con otros de ensimismamiento: «[El arte contemporáneo] no tuvo entre nosotros medios e difusión bastantes para fundamentar el movimiento juvenil posterior en unos hechos propios, y así los artisas incipientes de nuestra postguerra dirigieron su mirada al exterior como antes lo habían hecho los representados aquí». Lo que no se explica, naturalmente, son las razones de la interrupción de estos desarrollos artísticos en 1935, momento final de la exposición.

También Manuel Sánchez Camargo comparaba la exposición con los desarrollos artísticos de los años cincuenta ${ }^{18}$; lo hacía poniendo en paralelo la renovación de 1925 con la que había llevado a cabo la Academia Breve de Crítica de Arte en la que, por cierto, él mismo había tenido un papel relevante ${ }^{19}$. Por un lado, se daba carta de naturaleza a la moderada renovación de los años cuarenta, de la que los triunfos informalistas serían, a ojos del crítico, una consecuencia; por otro, se subrayaba un criterio historiográfico muy utilizado según el cual la historia del arte español se desarrolla, por causas congénitas, a saltos.

Estas actitudes crean un contexto de interpretación de la pintura abstracta que se dilatará en el tiempo y encontrará una respuesta muy favorable en la historiografía. Es una gran ofensiva de españolización del Informalismo en la que, además de la crítica de arte, otros agentes del sistema artístico tendrán un papel importante. En el horizonte ha de verse la radicalización del denominado «problema de España» durante el franquismo como verdadero banco de ideas y argumentos para esa españolización. Tampoco ha de olvidarse la necesidad, muy solicitada por los críticos, de exportar una imagen artística «moderna» del Régimen. La pintura abstracta fue, en el interior del país, más relevante de lo que podría parecer ${ }^{20}$.

\footnotetext{
16 Eduardo Westerdahl, Will Faber, Madrid, Ateneo, 1957.

17 Luis Figuerola-Ferretti, «ARTE. Arte español. 1925-1935», Arriba, Madrid, 13-4-60, p. 17.

18 Manuel Sánchez Camargo, «Pintura española: 1925-1935: los precursores», Cuadernos Hispanoamericanos, núm. 127, Madrid, julio de 1960, pp. 85-87.

19 Véase Manuel Sánchez Camargo, Historia de la Academia Breve de Crítica de Arte. Homenaje a Eugenio d'Ors, Madrid, Langa y Cia, 1963.

${ }^{20}$ Véase Francisco Calvo Serraller, España. Medio siglo de arte de vanguardia 1939-1985, Madrid, Ministerio de Cultura, 1985. La cuarta parte de las exposiciones reseñadas en este libro, el mejor banco de datos del arte español contemporáneo hasta hoy, entre 1955 y 1960 son de artistas españoles abstractos vivos en ese momento. No era, por tanto, la de la pintura abstracta una existencia marginal en el interior de España.
} 


\section{AUSTERA, EMOCIONAL, RELIGIOSA}

Frente a un Surrealismo frívolo y procaz (son epítetos que la crítica dedicó, en muchas ocasiones, a este movimiento), una de las mayores virtudes de la pintura abstracta será la austeridad. En 1952 Luis Felipe Vivanco escribía en Revista una glosa del arte de Mampaso que, siendo reveladora de los gustos del poeta, aclara las posiciones de una publicación siempe respetuosa con los argumentos orsianos. El modelo perfecto de abstracción, explica Vivanco, es el que combina la austeridad cubista (honradez) con una actitud lírica por la que sale la autenticidad del artista. $\mathrm{Ni}$ un arte que se reduzca a la estructura compositiva del cuadro, ni uno que suponga sólo improvisación; la solución ideal se encuentra en una mezcla entre forma y espíritu:

«Mampaso, alejado de todo exceso imaginativo, posee la otra imaginación, la formal, y permanece fiel a un cierto tipo de honradez, la que introdujo el cubismo y que consiste en pasar directamente de las realidades de los objetos a las de sus nuevas relaciones pictóricas. El premio de esta honradez es la autenticidad plástica de su lirismo» ${ }^{21}$.

Frente a otros modos de abstracción, el Informalismo sugiere un mayor peso emocional; así lo expresaba Cirilo Popovici a propósito de la obra de Juana Francés: frente a un arte abstracto «lógico racional y frío», la tendencia «aformal» tiende hacia un arte «puramente emocional ... que nada tiene que ver con la [lógica] del orden, de la razón, sino con la del sentimiento» ${ }^{22}$.

A propósito de la pintura de Rafols Casamada, Benet Aurell facilitaba un auténtico manual de instrucciones de uso, dirigido a los artífices de la abstracción: la pintura abstracta, decía, debe señalar «caminos vigentes sin atender forzosamente a la esencia de la pintura» ${ }^{23}$, había que moverse dentro de los límites de la tradición, excluyendo las actitudes iconoclastas y el cuestionamiento del estatuto tradicional de la obra de arte, algo ya muy viejo en 1956. Para Benet Aurell había que buscar el equilibrio perfecto entre lirismo y estructura del cuadro: «Geometría y lirismo, he aquí el secreto a voces de esta pintura».

La pintura abstracta es una manifestación de lo vivencial, del mundo interior, funciona como signo de una estética romántica y en ella las innovaciones están siempre al servicio de un discurso espiritual. La pintura cumple las funciones de siempre, que viajan ahora sobre lenguajes nuevos. Es una idea que posibilita la existencia de un arte religioso abstracto: «un arte sin palabras, sin imágenes que puedan distraer, le conduciría a la plegaria» ${ }^{24}$. El símil religioso es muy frecuente en la consideración de la pintura abstracta: «Tierra, Cosmos, Espacio, Signos y Astros: Modesto Cuixart va componiendo con rigor su canto a Dios» ${ }^{25}$.

Actitudes, éstas últimas, que deben relacionarse con un debate, realmente vivo, que se enmarca en la aceptación por la Iglesia Católica del arte abstracto. En 1952, Luis FiguerolaFerretti defendía muy claramente la entrada del arte abstracto en las iglesias y presentaba una tenue disidencia con la jerarquía religiosa, a la que recordaba la responsabilidad histórica de la Iglesia Católica en el desarrollo del arte occidental: el hecho de que la Iglesia hubiera sido tradicionalmente mecenas de los artistas más modernos en su momento, por eso pedía que se buscara

${ }^{21}$ Luis Felipe Vivanco, «Algunas exposiciones en Madrid», Revista, núm 37, 25-12-52, p. 37.

${ }_{22}$ Cirilo Popovici, Juana Concepción Francés y su poesía pictórica, Madrid, Ateneo, 1959.

${ }^{23}$ J. Benet Aurell, «Rafols Casamada y la auténtica abstracción», Índice de Artes y Letras, núm. 91, julio de 1956, p. 16.

${ }^{24}$ Manuel Sánchez Camargo, «Índice de exposiciones. Exposición de arte sacro en el Ateneo», Cuadernos Hispanoame ricanos, núm. 102, Madrid, junio de 1958, p. 410

${ }^{25}$ Luis González Robles, Cuixart, Madrid, Ateneo, 1960. 
«La coincidencia entre los fieles de una doctrina religiosa y los empeñados en la ardua tarea de encontrar nuevas expresiones capaces de condensar el nuevo espíritu de las formas, la impronta sensible de nuestro tiempo materializado en la mínima referencia de la línea y el color, del volumen escueto o la arista mural recia y contundente; es decir, en la menos sensual de las apariencias» ${ }^{26}$.

Además de solicitar claramente a la Iglesia Católica que se alinee claramente a favor de la modernidad, Figuerola afirma que la austeridad en el arte, tan defendida, entre otros, por Eugenio d'Ors, no es un término neutro, posee un sentido religioso que surge de modo automático, sin búsquedas excesivas. Por eso nuestro crítico podía defender sin reservas «la abstracción en arte religioso, con todo lo que de afinidad tiene hacia el símbolo litúrgico», como alternativa frente a «una imaginería de confitería y falso realismo hecha sin el menor acuerdo con la hagiografía» ${ }^{27}$.

En realidad es el inicio de una polémica que se resolverá en los años 60 , pero a lo largo de los 50 el arte abstracto, es sabido, se irá abriendo camino en las iglesias, a pesar del problema de Oteiza y Lucio Muñoz con el Santuario de Aránzazu en 1955, resuelto en 1962, en que «triunfó un sentido plástico mucho más nuevo y abstracto, verdaderamente expresivo del momento estético» ${ }^{28}$.

Uno de los más importantes documentos sobre el tema fue escrito por Luis Felipe Vivanco $^{29}$, que amplía las tesis tímidamente expuestas por Figuerola en el artículo citado más arriba. El poeta parte de la idea, formulada por Kandinsky pero reafirmada en las sesiones de la Escuela de Altamira, de que la espiritualidad es consustancial al arte abstracto; éste último, que incluía un gran abanico de soluciones estéticas, no era, necesariamente, un arte intelectualizado: la obra abstracta no reproduce la realidad, pero funciona como una «revelación» (un término bien significativo). Como la obra procede del espíritu, supone siempre una forma de «realismo trascendente». Las dos tendencias afines a la abstracción serán, para Vivanco, el Expresionismo y el Surrealismo, si el último resulta descartable por su contaminación poética y por su carácter «demasiado humano», el primero se considera de gran de valor pictórico por su génesis espiritual; Picasso sería básicamente expresionista,

«Su Mujer que llora ¿podría ser una Dolorosa?. Hay también en ella un arcaísmo desesperado y rebelde de dolor que la sitúa muy próxima a lo religioso» ${ }^{30}$.

No sería la última vez que Vivanco identificase arte religioso y expresionismo; mucho más que cualquier otro movimiento, el expresionista (Rouault o Nolde fundamentalmente) había conseguido «acercarse al evangelio» ${ }^{31}$. Vivanco postulaba una inserción de las nuevas tendencias artísticas dentro de la Iglesia y avalaba sus argumentos con citas de Couturier, promotor, como se sabe, de la Iglesia de Ronchamp, de Le Corbusier, y ferviente partidario de una presencia del arte moderno en las iglesias, especialmente desde una defensa de la pintura de Matisse. No es casual que, a lo largo de los años cincuenta, sobre todo al comienzo de la década, las ideas y la obra de Couturier se glosen con asiduidad en Revista ${ }^{32}$. La vinculación religiosa del arte moderno es un importante soporte ideológico para su aceptación. En el artículo citado

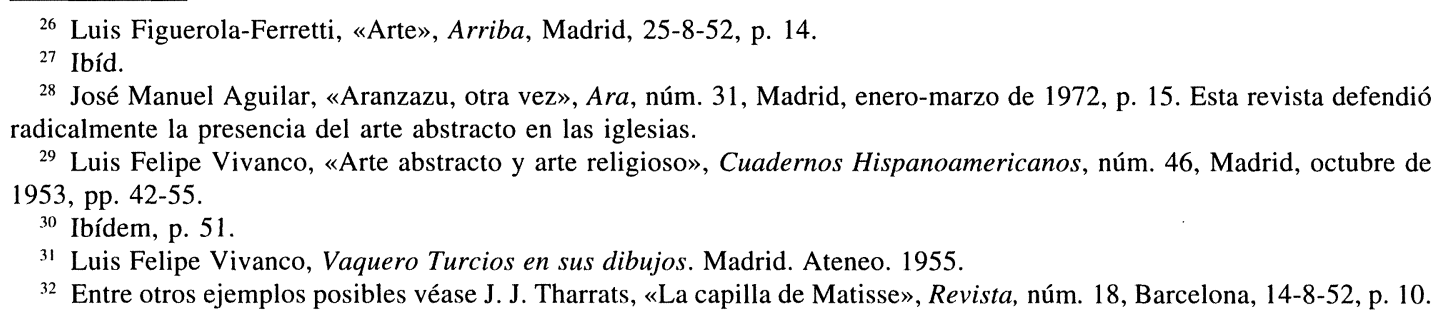

$A E A, \mathrm{LXXV}, 2002,297$, pp. 39 a 50 
más arriba, Figuerola sostenía que la Iglesia católica podía contribuir, con su apoyo, a que el arte abstracto dejara de ser minoritario. Es una vía de legitimación nada desdeñable ${ }^{33}$. No faltaron, sin embargo, posiciones opuestas como las muy conocidas de José María Pemán; también las hubo por parte de José Luis López de Aranguren, que solicitaba un arte religioso concreto y personalizado, en coherencia con una religión que reivindicaba un Dios hecho hombre ${ }^{34}$; otra cosa, decía, podría perjudicar al arte nuevo.

Abundaron las interpretaciones del arte abstracto desde el punto de vista religioso: sermones que pretendían señalar los caminos más deseables para el arte. En fecha tan tardía como 1966 Alfonso López Quintás señalaba a la abstracción los caminos del humanismo cristiano ${ }^{35}$; por carecer de figura, decía López Quintás, el arte abstracto no está irremediablemente vertido a un «caos informalista»; el poder ordenador de la forma, esencial en todo arte auténtico, evita la dispersión amorfa y garantiza, en el arte, las tensiones internas que caracterizan a todo ser vivo. El arte abstracto es positivo en la medida en que subraya la precariedad artística de las figuras y argumentos (supera los academicismos) y acentúa la potencialidad formal y expresiva de la materia en sí; intenta dejar al descubierto, «ascéticamente», el significado profundo de los símbolos arraigados en el alma humana. Caminar por la senda constructiva, reveladora de valores, sería la alternativa frente a la vía destructiva del nihilismo. Un riesgo, éste del nihilismo, que habían señalado Juan Eduardo Cirlot y José Camón Aznar ${ }^{36}$.

$\mathrm{El}$ arte abstracto será siempre preferible a las manifestaciones, realistas que presentan los bajos fondos, «como el cine neorrealista» ${ }^{37}$. Frente a una actitud que se obstina en presentar lo lacerante, el arte abstracto se ofrece como ideal, como modo de elevación sobre la materia concreta. Lo abstracto, sigue diciendo Camón Aznar, responde a un momento de desintegración progresiva de las formas y los elementos de la pintura: la luz con el Impresionismo, el volumen con el Fauvismo. Frente a esta vía se impone la ascesis, que deseca y geometriza los modelos y que es el principio motor de todas las abstraciones.

Hay, por lo tanto, una religiosidad implícita en el arte abstracto que puede reorientarse y que se relaciona con la idea de autenticidad; es esto lo que facilita, por empatía, el camino a lo religioso. Lo sugiró, entre otros, Juan Perucho, para quien el arte abstracto surge de los anhelos de una libertad que no se sitúa nunca en planos concretos:

\footnotetext{
«Esta libertad se traduce en las artes en una mística integración de sus principios, en un idealismo exasperado y ardiente que conduce al abandono de la realidad objetiva. En muchos casos, ello aparece casi con la intensidad de un substitutivo del sentimiento religioso ... Estos hombres que la mano de Dios para unos, la del diablo para otros, ha puesto en el mundo se llaman Mondrian y Malevitch, Kandinsky y Klee, Delaunay y Duchamp» ${ }^{38}$.
}

\footnotetext{
${ }^{33}$ El asunto queda muy claro en María Teresa González Vicario, Aproximación a la escultura religiosa en Madrid, Madrid, Universidad Nacional de Educación a Distancia, 1989.

34 José Luis López de Aranguren, «Sobre arte y religión», Cuadernos Hispanoamericanos, núm. 26, febrero de 1952, pp. 184-190.

${ }^{35}$ Alfonso López Quintas, «Posibilidades y riesgos del arte abstracto», Tercer Programa, Madrid, Octubre, noviembre, diciembre de 1966

${ }^{36}$ Juan Eduardo Cirlot, «La verdad y la máscara del arte nuevo. Respuesta a unos interrogantes sobre el arte del siglo XX», La Estafeta Literaria, núm. 155, Madrid, 22-11-58, PP. 8-9. José Camón Aznar, «El tiempo en Heidegger y su versión artística», Cuadernos Hispanoamericanos, núm. 97, Madrid, enero de 1958, pp. 5-17.

37 José Camón Aznar, «El hombre moderno ante el arte», Tercer Programa, núm. 2, Madrid, julio, agosto, septiembre de 1966.

${ }^{38}$ Juan Perucho, «Fautrier, o la búsqueda de lo absoluto», El arte en las artes, op. cit., pp. 43-44. Es significativa la velada alusión a Jean Paul Sartre, El diablo y Dios (1951).
} 


\section{TRÁGICA, ESPAÑOLA, POLÍTICAMENTE CORRECTA}

«Taüll representa tan sólo la conciencia de una sangre y de una historia» ${ }^{39}$. Así saludaba Joan Teixidor al grupo citado, que se presentaba como una «suma de unidades» en la medida en que lo componían siete pintores ya consagrados (Tharrats, Aleu, Guinovart, Cuixart, Tàpies, Muxart y Jordi Mercader), la crítica constituye un catálogo de la mayoría de los tópicos que informan la historia de la pintura catalana hasta nuestros días, «gozo por la materia» (Tharrats), «fondo mediterráneo» (Aleu), «aire austero y noble, clima casi moral»(Guinovart), «feria de una humanidad ingrávida» (Cuixart), «calidades minerales ... Quienes repiten incansablemente que el error de la pintura mal llamada abstracta es su deshumanización, encontrarían en Tàpies el mentís más rotundo a su gratuito criterio», «materia rica ... Gesto sobre la tela, contaminación violenta ... Lección de Nonell» (Muxart), «fuerza de un expresionismo dramático» (Mercader). El relato de la abstracción, tal como se configura a partir de 1955 tiene aquí un exponente significativo.

En general, son los aspectos dramáticos los que diferencian el Informalismo del Surrealismo, sirva como ejemplo un escrito de Joan Teixidor en el que se comparaban las obras de Joan Miró con las de Antoni Tàpies; aún aceptando la influencia inicial del primero sobre el segundo, Teixidor ponía el acento en las diferencias históricas entre los dos. El vacío mural de las pinturas de Tàpies sería, antes que nada, un punto de partida hacia lo dramático:

«Nada hay más opuesto a la tierra augural, primitiva e infantil a veces, de mágica fiesta mayor, de feria callejera, al portentoso mundo solar de Miró, que las silenciosas y dramáticas superficies de Tàpies donde sólo un pequeño rasguño, una leve insinuación gráfica interrumpe la maciza densidad de la tela» ${ }^{40}$.

Juan Perucho, una de las referencias ineludibles de la crítica de arte en la Barcelona de los años 60 , vinculó siempre la pintura abstracta a un sentimiento trágico. Perucho, poeta influido por el Surrealismo, no creía que Tàpies fuera un pintor informalista, pero subrayaba los aspectos dramáticos de su pintura:

«El mensaje de Tàpies es demasiado profundo, va más allá de la mera plasticidad de la materia o del objeto. El mensaje de Tàpies es la Muerte. La serena, segura desesperación de lo que va a fenecer. Nunca, desde las danzas macabras medievales, se nos había dicho con tanta intensidad lo irremediable y lo fatal de la Muerte» ${ }^{41}$.

Con todo, los argumentos que Juan Perucho atribuye a la pintura de Tàpies sirven para leer el informalismo español: situación en el ámbito de un existencialismo difuso, equidistancia de los realismos académico y socialista ${ }^{42}$, o anclaje en la realidad que impide que la abstraccción se precipite por el peligroso campo de lo decorativo:

«Libre e independiente, alejado por igual del realismo burgués y del llamado realismo socialista, en esta hora subversiva de la pintura de nuestro tiempo, místicamente lanzado a lo absoluto, su arte aparece como una serena meditación ante el horror de la nada ... Sin embargo, Tàpies consigue su alta tensión dramática directamente de lo real, de lo que está ahí, sin recurrir jamás a la fábula o lo discursivo» ${ }^{43}$.

\footnotetext{
39 Juan Teixidor, «Siete pintores bajo el signo de Taüll», Destino, núm. 928, Barcelona, 21-5-55, p. 33.

40 Juan Teixidor, «Las ultimas obras de Antonio Tàpies», Destino, núm. 1174, Barcelona, 6-2-60, p. 36.

41 Juan Perucho, «Antonio Tàpies o el hervor de lo inerte», El arte en las artes, Barcelona, Nauta, 1965, p. 11. El libro es una antología de sus críticas en la revista Destino.

${ }^{42}$ La equidistancia de los realismos, académico y socialista, se considerará una de las grandes virtudes del Informalismo, véase Anónimo, «Señoras y señores», Papeles de Son Armadans, «Monográfico EL PASO», op. cit.

43 Juan Perucho, «Antonio Tàpies o el hervor de lo inerte», op. cit., p. 11.

AEA, LXXV, 2002, 297, pp. 39 a 50
} 
El tema de la muerte estaba presente también en la obra de Cuixart. Junto a Tàpies, Cuixart habría desarrollado las estéticas de Dau al Set, cuyo inspirador último había sido Joan Ponç. La dimensión trágica viene, como hemos visto más arriba, de la tradición medieval, pero queda reforzada con el existencialismo, «Hay como un vértigo y una naúsea en todo».

\begin{abstract}
«Cuando éstos [Tàpies y Cuixart] lanzaron la pintura española por los anchos caminos europeos, lanzaron consigo el misterio de la muerte y de lo monstruoso y diabólico que habían vislumbrado simultáneamente con Ponç ... Tàpies y Cuixart penetraron también en esos pasadizos oscuros, en donde la muerte acecha a cada instante, y llegada que fue la hora del informalismo otorgaron a éste la dimensión trágica y misteriosa que le faltaba. Tàpies lo hizo como un clásico ... Cuixart como un barroco» ${ }^{44}$.
\end{abstract}

Tharrats, para Perucho, «se halla asociado al momento del despertar de la pintura viva de postguerra en España» ${ }^{45}$. El autor se refiere a Dau al Set que, como venimos viendo, se asocia en ocasiones no tanto al despertar como al fin de la vanguardia de anteguerra, como un epílogo ${ }^{46}$.

Los artistas contribuyeron especialmente a la visión trágica de la pintura informalista, e incidieron en su adscripción netamente española. El que podemos considerar como el primer relato canonizado del Informalismo español ${ }^{47}$ incluye una antología de textos de artistas que muestran una gran unanimidad en este sentido. La visión trágica sirve a planteamientos muy diferentes, y está bien presente, como es sabido, en la cultura española contemporánea; en todo caso podemos identificar españolismo y mito trágico. Estas posiciones nutrirán tanto la crítica como la Historia del Arte, en estos textos encontramos, además, posiciones de carácer historiográfico que se consolidarán después.

Para Antonio Saura el Informalismo era el corolario de un nuevo espacio pictórico que empieza con el Fauvismo y el Impresionismo, pero que tiene su antecedente más claro en el segundo ${ }^{48}$. La historia es lineal: va de la nueva estructuración del cuadro en el cubismo analítico o las obras más libres de Kandinsky, Klee y Miró al surrealismo dinámico (Matta y Gorki), y termina en Tobey, Wols, Dubuffet, Still, Rothko y Pollock; estos últimos representan, por primera vez en la Historia del Arte occidental, el espacio vacío, la materia informe, el gesto como auténtico protagonista del cuadro en sustitución de las formas.

Saura presenta la postguerra artística (europea) como una pugna entre una abstracción constructiva y otra expresiva ${ }^{49}$; entre las dos, una tercera vía que obedece a reglas que, como la armonía cromática, descienden de la composición clásica; es el caso de Stäel o Schneider, entre otros. Es lo que Saura considera una abstracción intermedia, aún no liberada de la tradición y en los parámetros del Impresionismo, que comportaba un concepto panteísta del universo ${ }^{50}$. La alternativa vendría dada por el protagonismo de la materia, «fundamento y fin del cuadro»; la materia incluye la propia pintura, amontonada o chorreante, y forma un verdadero espacio-materia; ésta es la auténtica renovación espacial para Saura. Este último modo pictórico se manifiesta en los pintores españoles bajo formas de «cósmica y barroca síntesis», ascesis de color y expresión, «telúrica violencia»; ejemplos claros serían Tapies o Millares. Obras ex-

\footnotetext{
44 Juan Perucho, «Modesto Cuixart o la heráldica de la muerte», El arte en las artes, op. cit., pp. 82-85.

${ }^{45}$ Juan Perucho, «La actividad creadora de J. J. Tharrats», El arte en las artes, op. cit., p. 106.

46 Así es para José María Moreno Galván, Introducción a la pintura española actual, Madrid, Publicaciones españolas, 1960

47 Papeles de Son Armadans, núm. 37, «Monográfico El Paso», Palma de Mallorca, abril de 1959.

48 Antonio Saura, «Espacio y gesto», Papeles de Son Armadans, núm 37, op. cit., pp. 47-63.

49 Una disyuntiva que plantaría mucho antes Enrique Azcoaga, «Ojeada artística a 1943», Escorial. Revisa de cultura y letras, núm. extraordinario Ojeada a 1943 y pronósticos para 1944, Madrid, 1944. Azcoaga consideraba que la pintura podía caminar hacia «una lírica pictórica» o bien hacia un constructivismo que «encarcela la esencialidad viva en una geometría llena de rigor».
} 
presionistas en que el gesto sirve para convertir el cuadro en un campo de acción inmediata («la tela es un campo de batalla»). Por un lado, lo español queda a salvo, por otro, el Informalismo no es un episodio más de la abstracción, sino un capítulo aparte en la misma.

Al contrario que en los casos aislados de expresionismo a lo largo de la historia (El Greco, Goya o Van Gogh) en el Expresionismo Abstracto las formas se destrozan para convertir el cuadro en una pulsión biológica. Frente a la abstracción constructiva, el Expresionismo Abstracto enfoca la realidad de forma inédita y totalizadora, sobrepasa el objeto en el acto dramático de pintar, en su éxtasis. Frente al orden clásico de la abstracción constructiva, el informalismo replantea el cuadro y

«propone, a través de su consciente visión del caos, el reflejo de un ansia de realidad absoluta donde no quepa separación posible entre mundo interior y mundo exterior, materia y espíritu, espacio y gesto» ${ }^{51}$.

La pintura informalista plantearía una ruptura con los últimos reductos del humanismo clásico, sería el fin de un proceso de dos siglos, una proposición de libertad total, y un proceso de renovación ${ }^{52}$. Sería esta pintura un acto de nihilismo, un grito hermoso entre tanto desastre.

El arte abstracto conservaba restos de tradición (orden del cuadro, valores cromáticos o pictóricos) que el Informalismo hace desaparecer. En todo el análisis hay una desautorización de las tendencias constructivas (Equipo 57) y, naturalmente, una afirmación de que la única modernidad posible radica en el Informalismo. El relato se repite en otros textos del artista, donde se incide en el carácter dramático del acto de pintar y se exalta el drama del artista ${ }^{53}$ :

«para no caer en un caos absoluto, para no llegar al suicidio, para no perder pie y no alejarme de una realidad tremenda, he escogido casi sin percatarme la única estructura que podía convenirme».

Saura obvia problemas muy concretos, por ejemplo el del propio papel del artista en la sociedad moderna, y muy concretamente, en la sociedad española de fines de los años 50 . Este discurso ambiguo, políticamente inofensivo, posibilita el apoyo estatal al Informalismo y el que hace que este movimiento actúe como dique frente a otros. Esta actitud posibilitará, desde los años setenta, un consciente olvido por parte de artistas más jóvenes de un arte españolizado de manera muy artificial. A los oidos de la oficialidad sonarían muy agradables las alusiones a San Juan de la Cruz o a Goya.

Viola, que procedía de la vanguardia histórica, volvió a España en los años 50 cambiando su nombre de José por el de Manuel y fue uno de los componentes de El Paso. Viola negaba al arte no sólo el carácter de «amena delectación», sino también el de «medio de expresión» ${ }^{54}$. Arte, decía, es un término que provoca naúseas por lo que encierra de «acomodaticio, adormecedor y evasivo». Se manifestaba contrario a toda forma de esteticismo, o decorativismo y, de manera explícita, hacía de Goya un profeta del Informalismo, anticipado en las pinturas negras.

Rafael Canogar, el componente más joven del grupo El Paso, atribuye a su pintura una función muy concreta: «encontrar nuevamente las verdaderas esencias de la pintura española de todos los tiempos» ${ }^{55}$. El pintor defiende la improvisación, que se concreta sobre todo en la

\footnotetext{
${ }^{50}$ Eugenio d'Ors había identificado impresionismo y panteísmo en Eugenio d'Ors i Rovira, No hay tal prehistoria, Santander, Escuela de Altamira, 1950.

51 Antonio Saura, «Espacio y gesto», op. cit., p. 55.

${ }^{52}$ Sólo dieciseis años después de que se escribieran estas palabras el informalismo se leería como el último episodio de la estética romántica, en Simón Marchan Fiz, Del arte objetual al arte de concepto, Madrid, Comunicación, 1974.

53 Antonio Saura, «Tres notas», Papeles de Son Armadans, núm. 37, op. cit., pp. 64-66.

${ }^{54}$ Manuel Viola, «Anti-arte», Papeles de Son Armadans, núm. 37, op. cit., pp. 67.

55 Rafael Canogar, «Tener los pies en la tierra», Papeles de Son Armadans, núm. 37, op. cit., p. 70.
} 
utilización directa del tubo de pintura; sin embargo, explica, las informas están condicionadas «al impulso que crea el estilo de una época». Defiende un estilo de aspecto caótico, que debe esperar la separación entre abstracción y figurativismo, efocando la realidad desde un ángulo diferente. Como se sabe, Canogar abandonó pronto el informalismo en aras de una figuración entre el realismo crítico y el pop, para volver después a una abstracción muy ordenada. En 1984 Canogar justificaba su escape del informalismo por agotamiento del movimiento y daba una definición interesante:

«El informalismo ... Es una obra que está basada en la expresión instantánea de sentimientos, era echar fuera sin pasar por el filtro de la razón los fantasmas que uno pudiera llevar dentro, y ese gesto existencial, esa tensión, no se puede mantener durante años, tiene una vitalidad corta ... No se puede mantener durante años sin que se convierta en retórica» ${ }^{56}$.

La interpretación dramática del arte es especialmente evidente en Saura (ya lo hemos visto) y en Millares; Papeles publicaba uno de los textos más conocidos del segundo ${ }^{57}$, que además ha servido tradicionalmente en el análisis de su pintura. El texto se mueve entre la declaración de intenciones y la interpretación histórica, en el primer aspecto se enuncia la idea la idea (repetida hasta la saciedad) de que «el arte sabe levantar pústulas hasta ahora ocultas en hipocresías». En el segundo el inevitable enlace con Goya, después del cual

«Sólo nos queda la auténtica vía social de los despojos materiales, el florecimiento del homúnculo como insidioso arquetipo» ${ }^{58}$.

Desde esta perspectiva el homúnculo sería un fenómeno del arte contemporáneo y no, como cabría esperar, de la pintura del propio Millares. El homúnculo está en la tradición del monstruo picassiano y de la afición de nuestro tiempo a las formas orgánicas, presentes en grupo en la obra de Pollock, como esperpentos en De Kooning, pero tambien en Dubuffet, en Appel o en Fautrier, sin olvidar las metamorfosis de Saura que convierte al sexo femenino en auténtica Venus ibérica de la misma fealdad. El homúnculo no es sólo una manifestación contemporánea, forma parte de las tradiciones españolas y, por eso, concede carta de naturaleza trágica a la pintura informalista:

«Presentar las cosas con pelos y señales ... sacar la momia de su saco, el gusano asqueroso de su sitio; traer a secar los ataudes reales a un sol de sombras humedecidas bajo el gran catafalco. Matarle la sonrisa campechana a Juan Ruiz. Actualizar la sucia amenaza que creó Gaspar Becerra» ${ }^{59}$.

Coherente con su época, independiente, «la pintura abstracta debe conseguir ... los valores pictóricos más esenciales ... Todos los movimientos realizados en nuestra época para dar al arte una dirección idealista o política han fracasado; el arte soviético, el nacionalsocialista y el pretendido arte social» ${ }^{60}$, es, por tanto, la pintura abstracta un arte puro, incontaminado, y una verdadera alternativa frente a otras tendencias más politizadas.

El informalismo es, para algunos críticos, un verdadero capítulo aparte que «podría ser considerado como una simple abstracción de texturas, pero, en realidad, supera este sentido parcial y constituye una verdadera mutación frente a lo abstracto» ${ }^{6}$. No es, sin embargo, una

\footnotetext{
56 Pilar Rubio, «El eterno retorno. Entrevista con Rafael Canogar», Lápiz, núm. 16, Madrid, mayo de 1984, pp. 30-36.

${ }^{57}$ Manolo Millares, «El homúnculo en la pintura actual», Papeles de Son Armadans, núm. 37, op. cit., pp. 79-83.

58 Ibídem, p. 80.

59 Manolo Millares, «El homúnculo en la pintura actual», op. cit., p. 82

${ }^{60}$ Cesáreo Rodríguez Aguilera, «Diálogos de arte. J. J. Tharrats», Revista, núm. 3, Barcelona, 1-5-52, p. 13.

${ }^{61}$ Juan Eduardo Cirlot, «La verdad y la máscara del arte nuevo. Respuesta a unos interrogantes sobre el arte del siglo XX», La Estafeta Literaria, núm. 155, Madrid, 22-11-58, pp. 8-9.
} 
aventura exenta de peligros: para el citado crítico habría dos opciones: retornar a «las fuentes de salud espiritual» o precipitarse por la «pendiente de las supresiones» que, Cirlot lo aclara, conduce directamente al nihilismo. Sería deseable lo primero, naturalmente, y la crítica se encargó de leer la pintura abstracta en esa dirección.

El mayor valor del arte abstracto es su despolitización: «El arte abstracto, nacido a comienzos del siglo xx, es ajeno a toda ideología no plástica. Carece de respaldos políticos determinados, y dentro de su ilimitada libertad, ha unido a artistas de opiniones, credos, razas y lenguas de extrema diversidad» ${ }^{62}$. Despolitizado no significa decorativo, al contrario, parece haber una relación de cercanía entre una neutralidad ideológica que garantiza la libertad artística y la reivindicación de una mayor intensidad del acento expresivo, frente, incluso, al arte abstracto que podríamos denominar «tradicional»: «Las imágenes de la pintura informal son imágenes del alma ... El arte otro renuncia a la frivolidad sensual de las franjas, los colorines y las monadas de los pintores abstractos» ${ }^{63}$.

\section{EPÍLOGO}

$\mathrm{Si}$, como ha escrito Dore Asthon, el Informalismo fue à rebours ${ }^{64}$, la crítica de arte lo leyó, en España, de un modo que lo aproximó al arte oficial; si fue, lo dice Dore Asthon de nuevo, la lingua franca de la postguerra occidental, la crítica, y los artistas, lo relataron en términos fuertemente españolistas. Los informalistas españoles integraron el grueso del envío a la Bienal de Venecia de 1958, «no sólo por su radical independencia estética, sino esencialmente por su singular problemática, de clara filiación ibérica» ${ }^{65}$, y obtuvieron uno de los éxitos más relevantes del arte español durante el régimen del general Franco. Ocho años más tarde estarían presentes en la Bienal de 1976, en la que no representaban ya a la España oficial; la pintura informalista se presentaba como una prueba de que «la imagen del esfuerzo cultural realizado durante el período republicano siguió vigente, míticamente, como punto de referencia sin el cual toda comprensión de la recuperación del vanguardismo bajo la dictadura sería imposible» ${ }^{66}$.

Es uno de los ejemplos más llamativos, no el único, de la doble visión que tuvo, en España, la pintura informal. El hecho, aún no suficientemente estudiado, ha de relacionarse con la calculada ambigüedad en la que navegó la política artística del franquismo y a la que, de modo más o menos consciente, contribuyó tanto la crítica de arte como los discursos de algunos artistas.

\footnotetext{
${ }^{62}$ Juan Antonio Gaya Nuño, «La verdad y la máscara del arte nuevo. Cuarto de espadas al arte abstracto», La Estafeta Literaria, núm. 156, Madrid, 29-11-58, pp. 1-2.

${ }^{63}$ Joan Fuster, «La verdad y la máscara del arte nuevo. Sobre algunos problemas del arte actual», La Estafeta Literaria, núm. 157, Madrid, 6-2-58, pp. 6-7

${ }^{64}$ Dore Asthon, «À rebours: la rebelión informalista», À rebours. La rebelión informalista [1939-1968] , op. cit., pp. 17 45.

${ }^{65}$ Luis González Robles, España en la XXIX Bienal de Venecia, Madrid, Dirección General de Relaciones Culturales, Pabellón de España, 1958

${ }^{66}$ Valeriano Bozal y Tomás Llorens (coords.), España, vanguardia artística y realidad social: 1936-1976, Barcelona Gustavo Gili, 1976, p. XIII.
}

AEA, LXXV, 2002, 297, pp. 39 a 50 